\title{
Taxonomizing non-at-issue contents
}

\author{
Thorsten Sander | Orcid: 0000-0002-0880-8843 \\ Institut für Philosophie, Universität Duisburg-Essen, Germany \\ thorsten.sander@uni-due.de
}

\begin{abstract}
I argue that there is no such thing as a unique and general taxonomy of non-at-issue contents. Accordingly, we ought to shun large categories such as "conventional implicature" (Grice), "F-implicature" (Horn), "CI" (Potts), "Class B" (Tonhauser, Beaver, Roberts \& Simons) or the like. As an alternative, we may, first, describe the "semantic profile" of linguistic devices as accurately as possible. Second, we may explicitly tailor our categories to particular theoretical purposes.
\end{abstract}

\section{Keywords}

non-at-issue content - projective content - Fregean colouring - conventional implicature presupposition - taxonomies

\section{Introduction}

The landscape of meaning or content (in the broadest possible sense of these terms) comprises two areas that are, on nearly all accounts ${ }^{1}$, rather well-charted: truth-conditional meaning on the one hand and conversational implicature on the other. Now somewhere in the middle between these two areas there is a muddy terrain, known under names such as "colouration" or "conventional implicature", that bears similarities to both of these areas: the contents we encounter there, contributed by items such as "but" and "bastard", are part of the linguistic meaning of certain items (and so similar to truth-conditional contents), but they are (like the

\footnotetext{
${ }^{1}$ Dissenters include Dummett, who thinks that the truth-conditional paradigm is too "modest" to count as a fullyfledged theory of meaning (see, e.g., Dummett 1996, 1-33), and Davis (1998), who argues that the Gricean account of indirect communication is deeply flawed.
} 
contents conveyed via conversational implicature) not part of the thought expressed by a sentence. They are, depending on your terminological preferences, not part of what is said, not at-issue, procedural, secondary, or non-truth-conditional. (Obviously, these concepts are not equivalent, more on which below.)

Since we shall see that these contents, as well as the linguistic devices carrying them, are quite heterogenous, it would be nice to start with a neat tree-like diagram that is based on principled taxonomy of them. However, the main tenet of this paper is that there is, probably, no such thing. There is, rather, a multitude of different classifications, depending on one's theoretical purposes, and that goes especially for broad top-level categories such as “conventional implicature" (Grice), "F-implicature" (Horn), "CIs" (Potts), "Class B" (Tonhauser et al.) or the like.

Let me point out two important things right here. First, since negative existential claims are notoriously difficult to prove, I should stress that my claim is not that there cannot possibly be a unique taxonomy of non-at-issue contents. My claim is, rather, that contents in general have so many intriguing properties that choosing one, or perhaps two, of them as a "principle of division" (as it was called in traditional logic) will generally involve more or less arbitrary decisions. Second, since some scholars, such as Bach (1999), have claimed that certain kinds of non-at-issue contents are a "myth", it is worth stressing that this is not how I would put it. What is a myth, though, is that broad categories such as "conventional implicature" cut linguistic reality at the joints.

\section{Five approaches to non-at-issue contents}

So instead of beginning with a classification, I shall start by having a brief look at some representative stages of the debate on non-at-issue contents. (Since "(non)-at-issue" is used in a bewildering variety of ways, I am not a big fan of the term. Nevertheless, for convenience, I shall continue to use it in what follows.) 
a) The first scholar who seems to have realized that there are such contents was Frege. Frege briefly discusses a large number of linguistic phenomena that are irrelevant to the expression of what he calls "thoughts" (Gedanken): the distinction between active and passive voice, words such as "alas" or "still", the difference between "dog" and "cur", between "and" and "but" and, more exotically from a contemporary perspective, the difference between "Frederick the Great won the battle of Rossbach" and "It is true that Frederick the Great won the battle of Rossbach" (see Logik, 152-153; Ged, 64; Ggf, 43). Since what Frege calls sense (Sinn) is the finest-grained kind of content that is still relevant from his logical point of view, he did not attempt to devise a positive account of these finer-grained phenomena, and he did not even use a single technical term for such contents. Instead, he uses a couple of metaphors such as "colouring", "wrapping" and "hint" (see SB, 31; Logik, 150-152). ${ }^{2}$

b) A couple of decades later, a very similar idea reappears in Grice's works under the heading of "conventional implicature". (It seems obvious that Grice was inspired by Fregean ideas, but due to his allergy to footnotes and references, shared by many of his contemporaries, there is no direct evidence for that.) Grice's stock of examples is, however, much more limited: as far as I see, there are only five words he ever mentioned as examples: "but", "therefore", "so", "moreover" and "on the other hand" $(1961,127 ; 1989,25,122,361-362)$. Unlike Frege, however, he offers at least a brief sketch of how these devices work: on Grice's view, such locutions are used to perform "higher-order speech-act[s] of commenting ... on the lowerorder speech-acts" $(1989,362)$. For instance, by uttering a sentence of the form " $p$, therefore $q "$, you are, according to Grice, asserting $p$, asserting $q$ and, at the same time, conventionally implicating that $p$ explains why $q$ holds.

\footnotetext{
${ }^{2}$ For more recent discussions of Frege's theory of colouring, or hinting, see Horn (2007); Sander (2019, 2021).
} 
c) Third, there is Potts's 2005 book on conventional implicature, which is also a reaction to Bach's (1999) claim that conventional implicatures simply don't exist. One of the striking features of Potts's account is his concession that expressions such as "but" or "therefore" do not carry conventional implicatures. Instead, he claims that a "fresh look at an old definition" $(2005,5)$ reveals two new types of examples: expressives such as "that bastard" on the one hand and supplements such as non-restrictive relative clauses on the other. As Horn (2007, 50) notes, this amounts to retaining Grice's brand name but altering the product.

d) Fourth, there is relevance theory. While most, perhaps all, scholars working in that framework are quite sceptical about Grice's notion of conventional implicature (see, e.g., Wilson \& Sperber 1993, 12-16; Blakemore 2002, 45-53), one might suspect that they were, to some extent, just selling Grice's old-fashioned product under a fancy new brand name ("procedural meaning", as opposed to "conceptual meaning"). The examples of procedural meaning that were initially offered by Blakemore (2002) and Wilson and Sperber (1993) are, after all, "discourse markers" such as "so", "after all” and "nevertheless". So it seems as though they were concerned with the very phenomenon that Grice attempted to elucidate. ${ }^{3}$ More recently, however, some relevance theorists have claimed that expressive terms such as “damn" also ought to be construed as examples of procedural meaning (Blakemore 2011; Wilson 2016), and this seems incompatible with Grice's notion of implicature. (For Grice, an implicatum is essentially a propositional content, and in uttering "That damn A is F" you arguably don't communicate "A is F \& I hate A", or the like.)

e) Fifth, Kaplan (ms) has argued for the claim that the content of many linguistic devices cannot be accounted for within what he calls a "semantics of meanings"; on his view, we

\footnotetext{
${ }^{3}$ Both Blakemore (2002, 48-49) and Wilson and Sperber (1993, 12-16) have offered arguments against the speech-act theoretic explanation Grice $(1989,362)$ sketched in his "Retrospective epilogue".
} 
should rather describe such devices by means of a "semantics of use". His examples include words such as "but", familiar from Frege and Grice, but also expressives such as "that bastard" and the farewell phrase "Goodbye!" (which has an illocutionary feel to it). Scholars such as Predelli (2013) and Gutzmann (2015) who have (partially) followed in Kaplan's footsteps have offered quite a few other examples of such "use-conditional items", as Gutzmann has called them: German modal particles, interjections, vocatives, slurs, nicknames, differences in register or style etc.

f) And, finally, there is a phenomenon that is sometimes taken to be a "close neighbor" (Abbot 2006, 2) of conventional implicature, i.e. (semantic or lexical) presupposition. However, since presupposition has been an extremely controversial topic for more than half a century now, I will attempt to steer around most aspects of that phenomenon in what follows. In later sections of this paper, I will argue, however, that the very distinction between presupposition and implicature might be rather artificial. ${ }^{4}$

When taking a look at all these linguistic phenomena that have been offered as examples of non-at-issue content, there are two things to note. First, there is some sort of collective uncertainty as to whether we ought to construe expressives as devices that carry non-at-issue contents. ${ }^{5}$ (According to Frege, expressives are instances of what he calls "colouring"; Potts similarly construes them as conventional implicatures. Grice, on the other hand, clearly did not think that his notion of conventional implicature might cover items such as "that bastard".) I think that all this is mainly due to the elusiveness of the phenomenon of

\footnotetext{
${ }^{4}$ Which is not to deny that such a distinction might be useful for some theoretical purposes; see my discussion of Frege's distinction between colouring and presupposition in $\S 6$.

${ }^{5}$ In what follows, the term "expressive" is used in a rather intuitive way: "expressives" are items that convey the speaker's feelings, emotions or, more broadly, non-doxastic attitudes while not describing them. On my usage, "Alas, Alfred came to party" contains an expressive device while "It made me sad that he came to the party" does not.
} 
expressing something, but I shall leave that for another occasion.

Second, it seems clear that the examples are quite heterogenous. They are, in fact, so heterogenous that none of the terms I mentioned above ("not part of the thought expressed", "not part of what is said", "non-conceptual", "secondary", "not at-issue", "not truthconditional") can be safely applied to all of them. Take the two terms "at-issue" and "truthconditional" as examples and consider, first, non-restrictive relative clauses. In the case of "Ames, who stole from the FBI, is now behind bars" (Potts 2005, 13), the information conveyed by the relative clause is plausibly non-at-issue, but this does not seem to be an example of non-truth-conditional content. Second, consider Kaplan's example “Goodbye!”. This is plausibly an example of non-truth-conditional content, but since the very point of uttering "Goodbye!" is to bid farewell to an addressee, what that word conveys isn't non-atissue. One might argue, however, that all examples fall under the complex concept encoded content that is either non-truth-conditional or non-at-issue. ${ }^{6}$ And perhaps they all concern a kind of meaning that goes beyond the speaker's main assertion. ${ }^{7}$

\section{Two recent taxonomies}

I have already pointed out that the class of non-at-issue contents is not particularly homogenous: "moreover" and "that bastard" do not seem to have much in common. But in some cases, even a particular category used by a single scholar comprises rather heterogenous devices. This is, I think, most evident in the case of Potts's 2005 account. On his view, the following two sentences both involve examples of what he calls "conventional implicatures" (or “CIs"):

\footnotetext{
${ }^{6}$ Needless to say, this is only true on a certain understanding of the term "at-issue". Unfortunately, "(non-)atissue" is, like "being", said in many ways: frequently, that term denotes what is conversationally the "main point" or the "question under discussion" (see Koev 2018 for some further distinctions along that dimension); sometimes it is supposed to mean roughly the same as Grice's notion of what is said or as Frege's notion of Sinn (Potts 2015, 168).

${ }^{7}$ Thanks to a referee for suggesting that to me.
} 
(1) Ames, who stole from the FBI, is now behind bars. (Potts 2005, 13)

(2) That bastard Conner was promoted. (Ibid., 157)

Now I don't wish to deny that these two sentences have something interesting in common, which is their radical projection behaviour ("scopelessness") as well as some related properties. (Compare Potts 2005, 41-44, I shall come back to this issue in §5.) But it seems equally clear that there are many salient differences between expressives and non-restrictive relative clauses. The content being conveyed by the relative clause of (1) is truth-conditional and propositional. The clause, moreover, plausibly expresses one of the speaker's beliefs and, as noted by Potts $(2005,24)$, conveys a thought that is asserted by the speaker. What is conveyed by "that bastard", in contrast, is essentially non-propositional, and so "that bastard" cannot possibly express a belief or convey an asserted thought. So it should be uncontroversial that we need a taxonomy of non-at-issue contents.

Let us have a brief look at two recent proposals, the first of which (due to Horn) is deeply rooted in the Fregeo-Gricean tradition and the second of which (due to Tonhauser et al.) is an attempt at a fresh start. Comparing these two proposals is instructive primarily because they are radically different. Other proposals currently on the market overlap to some degree. ${ }^{8}$ Horn's $(2013,161)$ classification of meaning relations in general is based on two questions that are relevant to non-at-issue contents:

(H-Q1) Does some content affect truth-conditions?

(H-Q2) Is that content asserted (or at issue)?

\footnotetext{
${ }^{8}$ See Gutzmann \& Turgay (2019), who distinguish four kinds of "secondary content”, and Potts (2015), who claims that there are eight "meaning classes", three of which concern non-at-issue contents. It is worth noting that none of these four proposals is based on exactly the same set of properties. Further, none of the scholars mentioned have offered explicit arguments for basing the taxonomy on the properties they have used as a base.
} 
Accordingly, there are, on his view, three types of phenomena:

Conventional or F-implicatures are truth-conditionally irrelevant and not at-issue. Examples include "but", honorifics such as French "tu" vs. "vous", active vs. passive voice, dativus ethicus, expressives etc.

$\underline{\text { Secondary assertions (such as non-restrictive relative clauses) affect truth-conditions }}$ and are at-issue.

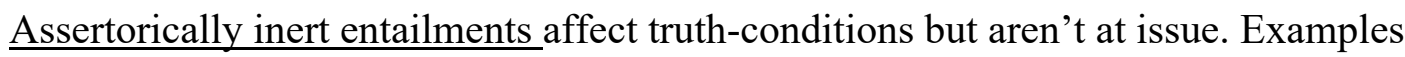
include "small words" such as "only" and "almost".

While Horn's classification does not include typical presupposition triggers such as clefts, factives or singular terms, the taxonomy Tonhauser, Beaver, Roberts, and Simons (henceforth: "TBRS") have offered is part of a sustained attempt to devise an account of projective contents in general (cf. Simons et al. 2010). Accordingly, the taxonomy is intended to cover (almost) ${ }^{9}$ all devices that have been construed either as presupposition triggers or as items carrying conventional implicatures. The proposal due to TBRS $(2013,75-76 ; 91-93)$ is based on two questions the exact formulation of which is quite technical. So I decided to simplify things a bit.

(TBRS-Q1) Must the content conveyed by an item be part of the common ground? ("strong contextual felicity")

(TBRS-Q2) Does an item that occurs in the scope of a belief operator carry a commitment of the respective speaker (as opposed to the person to whom the belief is ascribed)? ("obligatory local effect")

(TBRS-Q1) is concerned with the observation that particular items, standardly treated as

\footnotetext{
9 “Almost" because there are some alleged presupposition triggers (manner adverbs, for example) that are not mentioned by TBRS.
} 
presupposition triggers, cannot be used felicitously unless what these items convey is part of the common ground among the interlocutors. Uttering "Jerry is hungry, too" is appropriate only in a context in which the hungriness of some other person is salient. In contrast, a partially expressive sentence such as "That bastard Tom stole my wallet" can be used felicitously even if your interlocutors are ignorant about your attitude towards Tom. (TBRS-Q2) makes a distinction between items that can "scope out" of belief contexts and items that can't. For instance, in an utterance of "Tom believes that Jerry is tiny but dangerous" the idea of a "contrast" between tininess and dangerousness is part of the belief that is being ascribed to Tom. In contrast, the content of an apposition, as in "Tom believes that Jerry, a renowned cheese expert, is hungry", will be understood as a side-remark of the respective speaker, not as part of what Tom believes.

Combining these two properties, or questions, yields four classes of projective contents, labelled neutrally as A, B, C and D. Class B, for instance, comprises items that may scope out of belief sentences and that are not subject to strong contextual felicity:

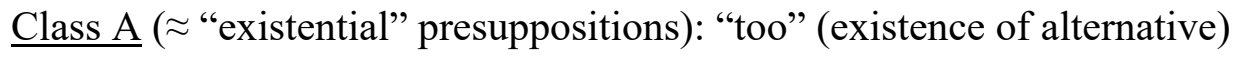

Class B $(\approx$ Pottsian “CIs"): supplements, expressives

Class C (many alleged presupposition triggers): "almost", “only", "know”, "stop"

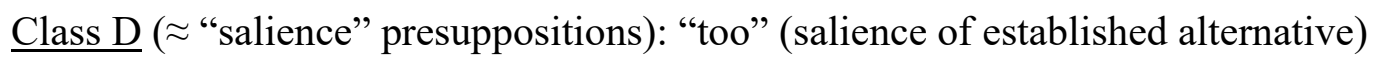

I will refrain from saying much about the virtues and vices of these two proposals. (One should note, however, that Horn's notion of F-implicature, being roughly as encompassing as Frege's notion of colouring, and Class B of the TBRS account, which is essentially identical to Potts's "CIs", are quite heterogenous categories that ought to be subtaxonomized.) All that matters, for present purposes, is that these two taxonomies classify linguistic devices, and the contents they convey, in vastly different and incompatible ways. 


\section{Why are there incompatible taxonomies?}

Why is that so? There are, I think, two reasons, the first of which is rather obvious: the two taxonomies are based on different properties or, in traditional terms, fundamenta divisionis. The less obvious and more fundamental reason is this: linguistic items arguably do not have what I shall call "dominant" properties. What is that supposed to mean? Think of biology as an example. Animals (and other living beings) have all sorts of biological properties: some animals are eusocial, some are parasites, predators or scavengers, while others aren't. Though all of these concepts refer to scientifically respectable properties (in contrast to "pet" or to the Borgesian taxon "animal belonging to the emperor"), none of them is actually used as a classificatory base in contemporary biology. The present taxonomy of animals in based on exactly one relation, which is, roughly, genetic similarity, and that would illustrate what I mean by a dominant property. ${ }^{10}$

To see why it will be difficult to single out such a dominant property of linguistic devices, consider again an example mentioned in the last section, i.e. non-restrictive relative clauses (NRRCs):

(1) Ames, who stole from the FBI, is now behind bars. (Potts 2005: 13)

Potts takes this to be an instance of what he calls "conventional implicature" essentially because NRRCs exhibit the same type of projection behaviour as expressives. No matter how deeply expressives or NRRCs are embedded, they may always be understood as a commitment, or comment, of the respective speaker. (Think of "It is possible that Smith believes that that bastard Ames, who stole from the FBI, is now behind bars" as an example.)

\footnotetext{
${ }^{10}$ There are, of course, theorists who advance some sort of taxonomic pluralism concerning species (for an overview, see Ereshefsky 2008). Nevertheless, biologists have managed to devise a taxonomy most parts of which are comparatively uncontested.
} 
Now compare Potts's account to a Fregean perspective on sentences such as (1). On Frege's view, expressive devices such as "that bastard" are examples of what he called "colouring"; a sentence like (1), in contrast, simply expresses two thoughts (SB, 44):

(1a) Ames is now behind bars.

(1b) Ames stole from the FBI.

Now Frege's reason for not lumping together NRRCs and expressives is this: he tailored his distinction between thought and mere colouring to his logical demands, and the category of colouring was motivated by his insight that a sentence may convey something that goes beyond its truth-evaluable content, which is the thought. Accordingly, coloured contents are alethically inert contents (see Sander 2019, § 3) and not projective contents. ${ }^{11}$

So it seems as though we are facing a choice: a taxonomy may be based either on the notion of projection or on the notion of truth, and both notions appear to be equally respectable. We might attempt, of course, to devise a taxonomy that is not based on one dominant property but instead on a small number of such properties, and that is precisely what scholars such as Horn and Tonhauser et al. have proposed.

Now the problem is this: such a strategy will only work if the number of significant properties is rather small, but this does not seem to be the case. On the assumption that neither Horn nor TBRS have chosen irrelevant properties, there are already four properties that must be taken into account in any case, which would yield a taxonomy with no less than 16 categories. And worse still, there appear to be at least seven additional properties relevant to taxonomizing contents, more on which in the next section. ${ }^{12}$

\footnotetext{
${ }^{11}$ Frege was aware of contents that project from under entailment-cancelling operators (see his discussion of the existential presuppositions of names: SB, 40), but projection behaviour is, on his view, not constitutive of the distinction between Sinn and colouring.

${ }^{12}$ In addition to the eleven properties, we also might distinguish between different kinds of at-issueness (see Koev 2018), and detachability (see Abbott 2006) may be important, too.
} 


\section{Eleven properties of contents}

So let us take a closer look at these properties, nearly all of which are familiar from the debate on non-at-issue contents. However, most of them have not been taken to be relevant to taxonomizing such contents. Those that have been employed as a classificatory base will reappear below, sometimes slightly modified: (H-Q1) and (H-Q2) correspond, respectively, to (Q7) and (Q9), (TBRS-Q1) and (TBRS-Q2) to (Q6) and (Q4). (The following list, like any other list, may make rather tedious reading, but I think it is important to realize just how many distinctions between non-at-issue contents we can make.)

(Q1) Communicative content: Does some linguistic item communicate a non-at-issue content? Quite a few languages offer two means of addressing an interlocutor: one may either use a formal or an informal pronoun (French "tu" vs. "vous" etc.). Now scholars such as Levinson $(1983,128-29)$ and Horn $(2013,168)$ have argued that this difference is to be explained in terms of conventional implicature: in uttering "Vous êtes le professeur" ("You [formal] are the teacher"), a speaker "conventionally but non-truth-conditionally indicates that the addressee is socially distant from ... the speaker" (Levinson 1983, 129). While it seems clear that an utterance of that sentence is infelicitous if the addressee is not socially distant from the speaker, there is reason to doubt that the difference between "tu" and "vous" can be explained in terms of the contents speakers intend to communicate (see Sander 2019, § 4). More plausibly, this may be an example of a (secondary) difference in meaning that ought to be accounted for solely in terms of felicity conditions. In this respect, the $\mathrm{T} / \mathrm{V}$ distinction appears to differ from pairs such as "dog" vs. "cur" (or "and" vs. "but"), where a difference in meaning corresponds to a difference in communicated contents. 
A more controversial example are certain presupposition triggers. ${ }^{13}$ In uttering "Sam read that novel, too", one seems to communicate, or mean ${ }_{N N}$, that a person who is not identical to Sam read a particular novel. In contrast, the existential presupposition triggered by a name does not appear to be an instance of communicative content. In uttering "Kepler died in misery" (SB, 40), you take Kepler's existence for granted, but you plausibly do not intend to communicate that Kepler exists or that the name "Kepler" refers to something.

Still more controversially, Lepore and Stone (2018) have argued that slurs and their neutral counterparts do not differ in communicational contents. Drawing on Frege's account of colouring, they claim that slurs are offensive "not because of what they communicate but rather because of interpretive effects their uses might exact" $(2018,205)$.

(Q2) Performativity: Does some linguistic device function as a ("tacit") performative? The very distinction between content and force is a highly contested issue, and so I am not sure whether there is a clear borderline between performative and non-performative devices, but intuitively there seems to be a difference between "therefore", which plausibly indicates that the speaker is doing something, i.e. drawing a conclusion, and "too", which seems to convey a kind of quasi-propositional content. Further plausible candidates for being (higherorder) performatives are the various locutions Bach (1999) has called "utterance modifiers", for instance items such as "in conclusion" or "for example". Again, there is a more controversial kind of example. Expressives such as "That damn NN" have been construed either as conventional implicatures (Potts 2005; Horn 2007) or as presupposition triggers (Schlenker 2007). However, one might also argue, as Rett (2021, forthcoming) recently has done, that such items encode that the respective speaker is doing something, i.e. expressing an emotional state.

\footnotetext{
${ }^{13}$ The question of whether presupposing is an example of non-natural meaning has not received much attention, but see Huntley (1975).
} 
(Q3) Projectivity: Is the content conveyed by some device projective?

Projectivity is the familiar phenomenon that some entailment-cancelling contexts (such as conditionals) function as "holes"14 when certain devices occur within their scope. An utterance of "If the Queen of England is bald, she wears a well-made wig" does not commit the speaker to the Queen's baldness but still to her existence. Some other contexts function as "plugs": for example, definite descriptions occurring as predicate nominals ("Macron isn't the King of France") generally do not carry existential commitments.

Now some scholars (Simons et al. 2010; see also Tonhauser et al. 2013) have argued that being projective and being non-at-issue is essentially the same property and, moreover, that the projection behaviour of certain devices may be explained by the fact that these devices convey non-at-issue contents. If that were correct, (Q3) would draw a clear line between atissue meaning on the one hand and projective contents in general (including presupposition triggers and conventional implicatures) on the other, which would make (Q3) redundant with respect to a taxonomy of non-at-issue contents.

However, there is at least one linguistic phenomenon (briefly mentioned above) that throws a monkey-wrench into that account. Consider, again, the T/V distinction: plausibly, the sentences " $\{$ Vous êtes/Tu es $\}$ le professeur" ("You [formal/informal] are the teacher") differ in linguistic meaning while expressing exactly the same proposition. However, since "vous" arguably does not convey any non-at-issue content, there is, trivially, no content that might project. Accordingly, there are secondary meanings that transcend the bipartite taxonomy atissue content vs. projective content. ${ }^{15}$

\footnotetext{
14 The hydraulic metaphors "hole" and "plug" are due to Karttunen (1973).

${ }^{15}$ Of course, the "politeness" (or the like) of "vous" cannot be contextually cancelled and may thus be taken to be "projective" in another sense of that word.
} 
(Q4) Scopelessness: Is the content conveyed by some device scopeless?

On all accounts, projection is characteristic of most non-at-issue contents. We may, however, distinguish two kinds of devices here: sometimes what is implied escapes through various holes such as negation or conditionals while being plugged by a belief context. This seems to be the case with many presupposition triggers and also with some instances of conventional implicature. By uttering "Bach believes that Shaq is huge but agile" you do not imply that there is some sort of "contrast" between hugeness and agility; you rather ascribe a belief with that content to Bach. And neither are you committed to Shaq's existence.

In contrast, by uttering "Potts believes that that damn Conner got promoted" you may be expressing your attitude towards Conner. Following Potts $(2005,42)$, this kind of (almost) "unpluggable" projectivity, exhibited by expressives and supplements, will be called “scopelessness" here.

(Q5) Common ground constraint: Does the content conveyed by an item need to be part of the common ground?

This property is familiar from a broadly Stalnakerian (2002) approach to presuppositions. The basic idea is this: an utterance of "The inventor of bifocals was short-sighted" is generally (but compare the next question) infelicitous if the proposition that there is a (unique) inventor of bifocals is not part of the common ground, i.e. (roughly) not something that is mutually believed by your interlocutors. In contrast, "Shaq is huge but agile" may be uttered even if your interlocutors do not believe that there is some "contrast" between hugeness and agility.

(Q6) Strong Contextual felicity: Is accomodation unavailable?

A well-known problem for Stalnaker's pragmatic account is the phenomenon of informative presupposition: by uttering "I've got to pick up my sister", you can felicitously communicate to an addressee that you have a sister even if that piece of information is new to that person 
(Stalnaker 1999, 52). Accomodation, an idea championed by David Lewis, is the standard solution to that problem: on Lewis's view, a presupposition that is required but missing normally "springs into existence, making what you said acceptable after all" (1979, 339). Lewis's idea has received mixed reactions (sometimes being described as a "magical process"; see Abbott 2006a, 6), but fortunately I can remain non-committal on that issue. All that matters, for present purposes, is something fairly uncontested: there are cases in which accomodation cannot come to the rescue. By uttering "It was Mary who broke the typewriter" (Soames 1989,605 ) you seem to imply that someone broke the typewriter, but as Soames notes it would be extremely "odd" to utter that sentence out of the blue. Similarly, when you are uttering "Sam is having dinner in New York tonight, too" (Kripke 2009, 273), you will be taken to have implied that some other person is having dinner in New York, but again it would be odd to attempt to inform an addressee that this is the case by uttering the above sentence. The proposition that someone other than Sam is having dinner in New York must be salient (in some way or another) when you are uttering the sentence. Accordingly, we ought to distinguish devices such as definite descriptions where accomodation is possible and devices such as "too" where it isn't. Following Tonhauser et al. (2013), I shall use the term "strong contextual felicity" for cases where accommodation is not available.

(Q7) Alethic inertia: Is the content conveyed by some device irrelevant to the truth of the sentence in which it occurs?

Like (Q5) and (Q6), (Q7) is intended to capture some intuitions surrounding the notion of presupposition. Compare Frege's analysis of "This cur howled the hole night" (Logik, 152) to what he says about "He who discovered the elliptical form of the planetary orbits died in misery" (SB, 39). On Frege's view, the latter sentence can't be true unless what the sentence 
implies ("There is somebody who ...") is actually the case. ${ }^{16}$ What is conveyed by "cur", in contrast, makes no difference to the thought expressed by the former sentence. If the dog is dear to your heart, your utterance will be infelicitous but still true.

(Q8) Inferential inertia: Is the content conveyed by some device inferentially irrelevant? From a Fregean point of view, there is no significant difference between (Q7) and (Q8). (Fregean thoughts, after all, are the bearers of truth-values as well as the relata of the entailment relation.) However, there might be reasons for assuming that some devices are alethically inert while being inferentially relevant. Such a line of thought has been explored by Kaplan (ms) under the heading of "truth-plus conservation" and, similarly, by Predelli $(2013,118)$, who uses the term “usability preservation”. For instance, one might argue that "Kaplan got promoted" follows from "That damn Kaplan got promoted" but not vice versa (Kaplan, ms), although these two sentences cannot possibly differ in truth-value.

(Q9) Assertoric Inertia: Is some content not part of what is being asserted by an utterance? As noted above, the term "assertorically inert entailments" is used by Horn $(2002 ; 2013)$ as a category that includes just a few exclusives ("only") and approximatives ("barely"), but I am using the term "assertoric inertia" in a wider sense here. For instance, compare "Shaq is huge but agile" to a NRRC such as "Shaq, who is a basketball player, is huge". The proposition that most huge people aren't agile does not seem part of the assertoric content of the former sentence, while the proposition that Shaq is a basketball player is plausibly part of what is asserted by the latter sentence. More generally still, assertoric inertia is a property trivially shared by all devices that convey expressive contents: by using expressives such "that bastard" or "cur" you convey contents that are essentially non-propositional and that thus

\footnotetext{
${ }^{16}$ The same goes for the items Horn has discussed under the heading of "assertorically inert entailments": "Only Pat passed" (Horn 2013, 170) can't be true unless somebody passed.
} 
cannot possibly be asserted.

Since lies are commonly thought to be assertions, it is worth noting here that certain items carrying non-at-issue contents may be assertorically inert while being "mendaciously" relevant. Uttering a sentence of the form " $p$, therefore $q$ " plausibly does not amount to asserting that $p$ is a reason for $q$, but uttering it when you believe that $p$ does not support $q$ may still count as lying (Sorensen 2017; compare Stokke 2017). Similarly, an utterance of "I've got to pick up my sister" does not seem to involve the assertion that the speaker has a sister, but when uttered by a sister-less speaker, the sentence may also be a lie (Viebahn 2020).

(Q10) Hybridness: Does some linguistic device convey different kinds of content at once? Next, we may contrast words such as "cur" or "but" on the one hand and "still" and "alas" on the other. Intuitively, "still" and "alas" are one-dimensional items, while in the case of "but" and "cur" two semantic dimensions appear to be entangled: "but" arguably mingles the contribution of "and" with the idea of some sort of "contrast", and "cur" seems to combine what is conveyed by "dog" with some expressive or evaluative content. Needless to say, there are some devices that have been construed both as hybrid and as non-hybrid: "thick concepts" such as "courageous" or "blasphemous" are salient examples (see, e.g., Väyrynen 2013).

(Q11) Elusiveness: Is the content conveyed by some device elusive (or ineffable)?

It is widely acknowledged that the semantic contribution of many devices that convey non-atissue contents is fairly elusive. Accordingly, there has been a debate on whether elusiveness is perhaps characteristic of non-at-issue contents in general or whether this is just an ordinary case of semantic indeterminacy (see, e.g., Blakemore 2011; Horn 2013, 160; McCready 2014, 66-68). I am not sure about such general ineffability claims, but what seems clear is that not all non-at-issue devices carry elusive contents. Consider the word "even". When uttering 
“Even Peter likes Mary", you convey one content that is indeed hard to pin down ("I didn't expect that ...", "It is improbable that ..." etc.) but also a content that is clearly non-elusive: "There is a person $\mathrm{x}$ such that: $\mathrm{x}$ is not identical to Peter \& $\mathrm{x}$ likes Mary". And, needless to say, the same goes for NRRCs and other "supplements" (compare Potts 2015, 188).

\section{Local Taxonomies and Semantic Profiles}

There are, then, at least eleven properties of linguistic devices that might be relevant to taxonomizing non-at-issue contents. How ought we to cope with such an embarras de richesse? First, we might attempt to reduce the number of properties by showing that some of them are dependent on some of the others, and in a few cases such a reduction may be feasible. One might argue, for instance, that elusiveness (Q11) is grounded in some of the other properties. In some cases (for instance in the case of certain honorifics), the elusiveness of what is conveyed may be due to the fact that there is no genuine communicative content in the first place (Q1). In some other cases, what is expressed may be an emotion rather than a belief and thus essentially non-propositional in nature (Q7). And, finally, there may be cases that are ordinary instances of semantic indeterminacy. That the contribution of some word is hard to pin down should, after all, only come as a surprise if we assume, implausibly, that our lexicon is generally "static" (compare Ludlow 2014).

In most other cases, there are, contrary to what one might expect, no straightforward logical relations between the properties. ${ }^{17}$ One might assume, for instance, that the three kinds of inertia I have mentioned (assertoric, inferential, and alethic) are part of a natural cluster of properties, and this is arguably true with respect to at-issue contents: the things we assert, the

\footnotetext{
${ }^{17}$ That is, with the exception of (Q3), (Q4), (Q5), and (Q6). The question of whether accommodation is available (Q6) arises only if there is a common ground constraint (Q5), and scopelessness (Q4) is just a more radical form of projectivity (Q3).
} 
things that are true or false, and the things standing in inferential relations appear to be precisely the same things here, i.e. thoughts or propositions. However, in the case of non-atissue contents these three properties seem to come apart: Frege's presuppositions and Horn's assertorically inert entailments (and, perhaps, NRRCs) are examples of alethically relevant contents that are not part of what is asserted. And if authors such as Kaplan and Predelli are right, then expressives such as "that bastard" may be inferentially relevant while being alethically inert.

Now, I clearly do not want to deny that some properties might be related to others in a way that makes them ultimately dispensable. The question of how, exactly, these properties interact indeed needs further attention, but as indicated above, attempting to answer it will involve quite a few complex theoretical issues. I am also skeptical that we will thereby achieve a significant reduction, and it is hard to see how a neat taxonomy could be based on more than a few properties (where "few" perhaps amounts to "not more than three"). Second, one might claim that many of the properties listed above are simply irrelevant to a taxonomy of secondary contents. However, in the absence of a suitable criterion of relevance, any choice of properties will be more or less arbitrary. Recall the two proposals mentioned in §3. It may seem tempting to claim that Horn's taxonomy is more "natural" than the proposal offered by Tonhauser et al., but "natural" here doesn't seem to mean more than "informed by certain Fregeo-Gricean ideas many scholars are accustomed to". And if there is indeed no general criterion of naturalness, relevance or the like, there are just two theoretical options (which are mutually compatible and ought to be combined).

First, we may devise "local" taxonomies, explicitly tailored to a specific theoretical purpose. It is one of Frege's insights that relativizing our taxonomies ought to be the default case. Frege never maintained that the distinctions he made from a logical point of view cut linguistic phenomena at the joints: 
It is just as important to refrain from making distinctions that do not go to the heart of the matter, as to make distinctions which concern what is essential. But what is essential depends on the purpose. If one is concerned with beauty in language, what is indifferent to the logician may be just what is important. (Ged, 64, my translation) ${ }^{18}$

For instance, from Frege's logical point of view, alethic inertia is arguably the central property: Frege's notion of colouring covers any communicative phenomenon that is irrelevant to the expression of thoughts, including not only devices that are similar to conventional implicatures, but also things such as psychological or "lexical effects" (see Cappelen 2018, 122-134) which haven't got anything to do with meanings, even on a broad understanding of that term. Fregean presuppositions, in contrast, are alethically relevant: sentences containing proper names cannot, on Frege's view, express true thoughts if the names are vacuous. Thus, on Frege's account, we ought to distinguish two classes of phenomena that differ from thought-like contents: a very small and homogeneous class of presuppositions and a rather large and heterogenous class of colourings (see Sander 2019, 2021, 2021a). If, one the other hand, your purpose is to devise a formal semantics applicable to non-regular contents, then projectivity is perhaps what you ought to focus on. (Such a focus, however, will make the borderline between presupposition and conventional implicature rather blurry.)

Second, we may place the names of large categories such as "conventional implicature", "presupposition" (but also "F-implicature", "Class B" etc.) on a revised index verborum prohibitorum and focus instead on the properties themselves. This is, roughly, the strategy recently advocated by Potts:

What we need are rich theories of properties like "conventional," "backgrounded," and "projective," the way those properties interact, and the effects of those interactions on language and cognition. Clustering different combinations of these properties using

\footnotetext{
${ }^{18}$ Frege's point here is of course rooted in the traditional theory of “division". See Keynes (1894, 461): “A given class may of course be divided in different ways according to the particular attribute or attributes whose variations are selected as differentiating its various species."
} 
labels like 'presupposition' and 'implicature' does not necessarily help with these theoretical challenges, and it might even lead us astray, by suggesting boundaries where there are none. (Potts 2015, 192-193.)

So instead of claiming that, say, "too" is a presupposition trigger and that "but" carries a conventional implicature, we may devise a finer-grained description of the "semantic profile" (as I shall call it) of certain words, taking account of all the questions, or properties, listed in the last section. For reference, let us briefly recapitulate these properties. (Since elusiveness is itself a somewhat elusive issue, I will ignore it in what follows.)

$\begin{array}{ll}\text { (Q1) Communicative content } & (=\mathrm{CC}) \\ \text { (Q2) Performativity } & (=\text { Perf }) \\ \text { (Q3) Projectivity } & (=\text { Proj) } \\ \text { (Q4) Scopelessness } & (=\text { Scope) } \\ \text { (Q5) Common ground constraint } & (=\mathrm{CGC}) \\ \text { (Q6) Strong contextual felicity } & (=\mathrm{SCF}) \\ \text { (Q7) Alethic inertia } & (=\mathrm{Al}-\mathrm{I}) \\ \text { (Q8) Inferential inertia } & (=\mathrm{I}-\mathrm{I}) \\ \text { (Q9) Assertoric inertia } & (=\mathrm{As}-\mathrm{I}) \\ \text { (Q10) Hybridness } & (=\mathrm{Hyb})\end{array}$

There are various ways of representing a semantic profile (one might, for instance, mimic the way semantic features are notated), but for present purposes a detailed description might be the best option. So let us take a closer look at five devices that have been offered as examples of non-at-issue content. "Cur" is one of Frege's examples of what he calls "Färbung"; “therefore" is, on Grice's view, an instance of conventional implicature; NRRCs are Pottsian CIs; the distinction between formal and informal pronouns such as German "du" and "Sie" has been described, by Levinson (1983, 128-129) and Horn (2013: 168), as a further example of conventional implicature; and, finally, the existential commitment carried by (it-)clefts has been described in a variety of ways, often as an example of presupposition. I think these five 
examples suffice to show that items contributing non-at-issue content do not naturally fall into larger categories such as conventional implicature. (Note that expressives, NRRCs, and "therefore" have also been construed as presupposition triggers.)

(i) (Q1) When speakers use "cur", they plausibly intend to convey an emotional attitude, which is an example of communicative content. (Q3/4/7/9) Like other expressives, "cur" is scopeless (and so trivially projective) and also alethically as well as assertorically inert. ${ }^{19}$ (Q5/6) "Cur" is clearly not subject to a common ground constraint and so question (Q6) does not arise. (Q10) Finally, it is obviously a hybrid term.

The two remaining questions are more difficult to answer. (Q2) As noted above, pure expressives such as "that bastard" have been construed as performatives, and if successful such accounts might be extended to cover hybrid expressives such as “cur". (Q8) And whether expressives such as "cur" are indeed inferentially inert depends on complex issues in the philosophy of logic: on Frege's view, the emotive contribution of "cur" does not matter from a logical point of view, while for Kaplan expressives are relevant to what he calls "truthplus preservation".

(ii) (Q1) By employing "therefore", one communicates that there is a particular explanatory relation between two contents. (Q3/4) "Therefore" is clearly projective but not scopeless ("If he is an Englishman and therefore brave, then ..." vs. "Berta believes that Albert is an Englishman and therefore brave"). (Q8/9/10) "Therefore" is plainly non-hybrid and inferentially as well as assertorically inert.

The four remaining questions are more intricate. (Q7) On Bach's $(1999,330)$ view,

\footnotetext{
${ }^{19}$ But see Sorensen (2017, 111-112) who argues, unconvincingly I think, that by using the word "nag”, one makes a (secondary) assertion about one's disapproval of a certain horse. Similarly, Burge $(2012,63)$ has toyed with the idea that the word "steed" may be connected with (Fregean) "[t]houghts about heroism", and Potts $(2005,158)$ characterizes the contents of items such as "that jerk Chuck" as "speaker-oriented (nonpresuppositional) assertions".
} 
"therefore" is not a convincing example of an item carrying a conventional implicature since "it seems that the truth of the utterance ['He is an Englishman; he is, therefore, brave'] does require that the second proposition be a consequence of the first". Now truth-value intuitions in such cases are notoriously shaky, but I would assume that Grice was on the right track here: "strictly speaking" (Grice 1989, 25), the truth of the utterance does not depend on what is indicated by that adverb. (Q2) Though it seems plausible that "therefore" is some kind of force-indicator since it encodes what one is doing, i.e. drawing a conclusion, it has also been characterized as a presupposition trigger (Stokke 2017). (Q5/6) Finally, "therefore" may be subject to a (weak and accommodable) common ground constraint: employing "therefore" when the relation between two contents is highly controversial seems infelicitous: if one intends to make a controversial claim of that kind, one ought to resort to locutions such as " $p$ explains why $q$ is the case", instead of " $p$, therefore $q$ ".

(iii) (Q1) The content of a NRRC is clearly part of what a speaker communicates by uttering a sentence. (Q3/4) NRRRCs exhibit essentially the same projection behaviour as typical expressives; they are projective and also scopeless. (Q5/6) Since NRRCs are not subject to a common ground constraint, (Q6), again, does not arise. (One might argue, however, that using a NRRC is felicitous only if the speaker has reason to assume that the content conveyed by it is not part of the common ground.) (Q8/10) NRRCs are plainly non-hybrid, and the contents they convey are plausibly inferentially relevant. (Q2), (Q7) and (Q9) are more controversial. (Q7) Consider an example due to Bach (1999, 345): “Ann's computer, which she bought in 1992, crashes frequently". Now suppose that Ann bought her computer in 1993. Would that make the whole sentence false? As Bach notes, we would probably tend to ignore the NRRC here so that the sentence would still count as true. In other cases, a NRRC may be so salient that its content will have an impact on the truth-value of the sentence as a whole ("Queen Elizabeth, who brutally murdered her husband, 
does not like garlic.") Accordingly, the alethic relevance of NRRCs appears to be subject to complex contextual factors. (Q9) Since NRRCs cannot be used felicitously to answer questions (A: “Where does C live?”, B: “C, who lives in Antibes, is a dentist”; see Gutzmann \& Turgay 2019,3), they seem to differ from prototypical asserted contents. ${ }^{20}$ On the other hand, a speaker is explicitly committed to the content of a NRRC (see Potts 2005, 24). So depending on one's preferred notion of assertion, the content of a NRRC may or may not be part of what is asserted by an utterance. (Q2) At first glance, the contribution of NRRCs seems to be plainly non-illocutionary. Since however, as noted by Horn $(2013,164)$, explicit performatives may be inserted into NRRCs ("The bank bailout bill, which I hereby pledge to support, is immoral and unconscionable"), there may be reason to construe the overall content of a NRRC not as a mere proposition, but instead, following Horn, as a secondary assertion.

(iv) (Q1) As briefly argued above, the T/V distinction is perhaps best seen as a mere matter of social propriety, and not as a matter of content proper. If that idea is on the right track, then most of the remaining questions, which concern the status of certain contents, simply do not arise. (However, some of the questions might be rephrased such that they become applicable to items such as "vous". For instance, though "vous", in contrast to "cur", does not communicate an alethically inert content, it is alethically inert: whether you choose "vous" or "tu" has no effect on the truth of a sentence.)

(v) (Q1/2) A cleft sentence such as "It was Bill who drank the last beer" plausibly conveys the propositional (and thus non-illocutionary) content that someone drank the last beer. (Q3/4) That content projects ("It wasn't Bill who ...") but is clearly not scopeless ("If there was any

\footnotetext{
${ }^{20}$ However, "C, who is a dentist, lives in Antibes" also seems quite odd as an answer to the above question. Perhaps, as a rule of thumb, an answer should not contain any unnecessary material. (That rule is, of course, a corollary of Grice's $(1989,26)$ second maxim of Quantity: "Do not make your contribution more informative than is required.")
} 
beer left, then it was Bill ...”). (Q5) Uttering such a cleft seems infelicitous if the content it contributes is not part of the common ground. (Q7/8) In the case of some other alleged presupposition triggers (for instance, in the case of existential presuppositions triggered by names), truth-value intuitions are somewhat shaky, but in the case of clefts, things seem to be clear: since the presupposition carried by "It was Bill who drank the last beer" is simply the existential generalization of its at-issue content, the sentence cannot possibly be true if the content presupposed by it is false. (Q9/10) Since what is implied by a cleft is "backgrounded", the proposition conveyed by it is plausibly not part of what is asserted by it. Further, a cleft clearly does not mix different kinds of content.

The only questions that are somewhat trickier are (Q6) and (Q8). (Q6) I noted above that accommodation seems unavailable in cases such as "It was Mary who broke the typewriter". On the other hand, there appear to be examples of accommodable clefts, and some corpusbased studies even suggest that the majority of it-clefts is informative (see Tonhauser 2015, 89-91). So, clefts do not universally seem to have the property of strong contextual felicity. (Q8) Although the proposition that someone drank the last beer plausibly follows from "It was Bill who drank the last beer", the cleft itself still seems inferentially inert. The aforementioned proposition, after all, follows from "Bill drank the last beer" in a single step of existential introduction.

The following table summarizes these findings. ("Y" and "N" obviously stand for "Yes" and "No"; an additional question mark indicates potentially problematic answers; a mere question mark indicates that there is a serious controversy in the literature; and "IA" means that a particular property is inapplicable to an item.) 


\begin{tabular}{|c|c|c|c|c|c|c|c|c|c|c|}
\hline & $\begin{array}{c}\text { (Q1) } \\
\text { CC }\end{array}$ & $\begin{array}{l}\text { (Q2) } \\
\text { Perf }\end{array}$ & $\begin{array}{l}\text { (Q3) } \\
\text { Proi }\end{array}$ & $\begin{array}{l}\text { (Q4) } \\
\text { Scope }\end{array}$ & $\begin{array}{l}\text { (Q5) } \\
\text { CGC }\end{array}$ & $\begin{array}{l}\text { (Q6) } \\
\text { SCF }\end{array}$ & $\begin{array}{l}\text { (Q7) } \\
\text { Al-I }\end{array}$ & $\begin{array}{c}\text { (Q8) } \\
\text { I-I }\end{array}$ & $\begin{array}{l}\text { (Q9) } \\
\text { As-I }\end{array}$ & $\begin{array}{c}\text { (Q10) } \\
\text { Hyb }\end{array}$ \\
\hline "cur" & $\mathrm{Y}$ & ? & $Y$ & $\mathrm{Y}$ & $\mathrm{N}$ & IA & Y & Y? & $Y$ & $Y$ \\
\hline "therefore" & $Y$ & Y? & $Y$ & $\mathrm{~N}$ & Y? & $\mathrm{N}$ & Y? & $Y$ & $Y$ & $\mathrm{~N}$ \\
\hline NRRCs & Y & ? & Y & Y & $\mathrm{N}$ & IA & $?$ & $\mathrm{~N}$ & $\mathrm{~N}$ ? & $\mathrm{N}$ \\
\hline $\mathbf{T} / \mathbf{V}$ & $\mathrm{N}$ & $\mathrm{N}$ & IA & IA & IA & IA & IA & IA & IA & IA \\
\hline Clefts & Y & $\mathrm{N}$ & $Y$ & $\mathrm{~N}$ & Y & $\mathrm{N}$ & $\mathrm{N}$ & $Y$ & $Y$ & $\mathrm{~N}$ \\
\hline
\end{tabular}

Two important lessons can be drawn from the above discussion of some examples. First, answering the question of whether some device does have a particular property is, in many cases, more difficult than might be supposed. The answer will often depend on complex issues surrounding notions such as assertion, inference, and illocutionary force, and a taxonomy will inherit any problems that are raised by the properties on which it is grounded. Second, and crucially, there are no examples where we would find exactly the same pattern of answers, which makes it unlikely that the properties form larger "natural" clusters. So even if there were a "natural" class of conventional-implicature-like phenomena (such as "Fimplicatures" or "Class B"), such a large category would blur many subtle (and some less subtle) differences between some of the items: construing "cur" and the T/V distinction as cases of (Hornian) F-implicature would amount to ignoring many of their specific properties; and treating "cur" and NRRCs as elements of Class B would have the same effect.

\section{Semantic Relativism}

If I am right, there is probably no such thing as a unique and general taxonomy of non-atissue content - a claim that might be called "taxonomic relativism". That claim accords well with similar (but more general) ideas that have recently been defended by Chalmers (2011) and Saul (2012) under the heading of "semantic relativism". For instance, Saul claims that "(many of) the various notions [of what is said] currently at use in the semantic-pragmatic 
distinction disputes should be viewed not as competitors, but as notions suited for different purposes" $(2012,137-138)$. The pacifying virtues of such a perspective become apparent when we think of the debate on minimalism and contextualism, in which the semanticpragmatic distinction has been discussed, in part, in a rather polemical way (see, e.g., Recanati 2006). As far as I see, almost everyone would agree that there are, roughly, seven levels of specifying what is conveyed by a sentence S:

1) what is conveyed by S solely in virtue its linguistic meaning

2) what is conveyed by a disambiguation of S (if S contains ambiguous terms)

3) what is conveyed by $\mathrm{S}$ once we have determined the reference of the indexicals or demonstratives contained in $\mathrm{S}$ (if there are any)

4) what is conveyed by a "completion" of $S$

5) what is conveyed by an "expansion" of $S^{21}$

6) what is conveyed by the non-at-issue contents of $S$

7) what is conversationally implicated by (an utterance of) $\mathrm{S}$.

Assuming that each level incorporates all the contents of lower levels, which of these levels corresponds to "what is said", to "semantic content" or to "propositional content"? Unless a particular purpose has been made explicit, anything between 1) and 5), perhaps even 6), may appear to be a reasonably plausible candidate. If, however, we specify particular purposes, certain parts of the debate on contextualism might turn out to be merely verbal disputes. First, consider Frege's notion of thought, which seems to correspond either to level 4 or 5. This is so since Fregean thoughts are essentially bearers of truth-values and since, on Frege's view, a sentence such as "It is raining" does not express a truth-evaluable thought unless time and place have been supplied (Logik, 146). Second, think of Cappelen's and Lepore's defence of “insensitive semantics”. One of Cappelen's and Lepore's master arguments for the kind of minimalism they advocate is based on the Fregean idea that "the same content can be expressed, claimed, asserted, questioned, investigated, etc. in radically different contexts"

\footnotetext{
${ }^{21}$ On the difference between completions and expansions, see, e.g., Bach (1994); Saul (2012, 32-33).
} 
$(2012,152)$, and on their view, the kind of content that can be shared across contexts, "semantic content", corresponds to level 3. Third, consider Borg's defence of yet another version of minimalism (2004). Unlike Frege, who is concerned with truth-bearers, and Cappelen \& Lepore, who are concerned with successful communication, Borg is concerned with psychology and the philosophy of mind. Her main tenet is that only a narrow notion of "semantic content" allows "linguistic meaning to be treated as a proper part of a modular language faculty" $(2004,74)$. Obviously, such a psychologically informed notion of semantic content does not have to coincide with other notions. Fourth and finally, there is Saul who, unlike the other scholars I have mentioned, does not think that there is only one salient notion of semantic content. Rather, she claims that there are several notions, suitable for different theoretical aims, and on her view, it is level 4 that corresponds to the notion of what is said that is needed for understanding the difference between lying and misleading. Accordingly, there are at least four salient (and plausibly non-equivalent) notions of content:

a) the kind of content that functions as the primary bearer of truth and falsity (Fregean Gedanken)

b) the kind of contextually invariant content that enables interlocutors to grasp the very same content (Cappellen's \& Lepore's "semantic content”)

c) the kind of content that is associated with modular capacities (Borg's "semantic content")

d) the kind of content a speaker S believes to be false when S is lying (Saul's "what is said")

Notions such as "semantic content" or "propositional content" suggest clear-cut distinctions between certain phenomena while there are, arguably, several distinctions, depending on the theoretical problems one is attempting to solve. Similarly, large categories such as "conventional implicature" or "presupposition" presuppose the existence of clear borderlines while the actual debate on such categories suggests that the borders are either extremely 
vague or that there aren't borders in the first place. ${ }^{22}$ The debate on non-at-issue contents exhibits, after all, some re-emerging dialectical patterns (where "C" stands for some top-level category in what follows):

i) Scholars have claimed that some device that used to be construed as an instance of $\mathrm{C}_{1}$ is indeed an instance of $\mathrm{C}_{2}$ (for instance, NRRCs, expressives and words such as "even", "only" etc. have been presented as examples of conventional implicature as well as examples of presupposition)

ii) Scholars have proposed, more radically, to re-sort phenomena in a way that differs significantly from previous proposals (Potts 2005; Tonhauser et al. 2013)

iii) Finally, scholars have claimed that some category $\mathrm{C}$ is a myth (Boër \& Lycan 1976; Bach 1999)

The fact that the debate on non-at-issue contents has proceeded like that seems to indicate that the textbook categories to which we are accustomed, but also new categories proposed more recently are inherently unstable, and they are indeed unstable since lumping some phenomena together amounts here to ignoring some salient differences between them. Categories such as conventional implicature may not only lead to disputes that are, to some extent, merely verbal; they sometimes also mask what scholars agree upon. To see that, consider locutions such as "moreover" or "by the way", both of which are Bachian "utterance modifiers". On Bach's view, such locutions serve to make second-order comments on what is said. Now Bach's account is, as he acknowledges $(1999,328)$, not essentially different from Grice's analysis of such locutions. The only difference between Grice and Bach concerns the question of whether "to call these second-order speech acts implicatures" (Bach 2006, 474), and one might argue that this question is moot. What counts is that there are indeed locutions that

\footnotetext{
${ }^{22}$ Kripke once claimed that the notion of presupposition is like the notion of pornography: "we all recognize it when we see it, even if we can't say exactly what it is" $(2009,367)$, which would mean that there is a largely unproblematic "intuitive concept of presupposition". I don't think that many contemporary scholars would concur with him here.
} 
function as second-order performatives, and I see no reason why lumping them together with other phenomena might enhance our understanding of them. On the other hand, such lumping could only be seriously flawed if it would infringe on some "natural" borderlines between certain non-at-issue contents, and if I am right, there aren't such borders.

\section{Acknowledgments}

Thanks go to several participants of Raphael van Riel's research seminar and to an anonymous referee for Grazer Philosophische Studien. Funded by the Deutsche Forschungsgemeinschaft (DFG, German Research Foundation) - 439302327.

\section{References}

Abbott, Barbara 2006. "Where Have some of the Presuppositions Gone?" In: Drawing the Boundaries of Meaning, edited by Betty J. Birner \& Gregory Ward, Amsterdam, PA: John Benjamins, 21-30.

Abbott, Barbara 2006a. "Unaccommodating presuppositions: A neo-Gricean view." URL = $<$ https://semantics.uchicago.edu/kennedy/classes/f09/semprag1/unaccompresupps.pdf $>$

Bach, Kent 1994. "Conversational Impliciture.” Mind \& Language 9, 124-162. DOI: 10.1111/j.1468-0017.1994.tb00220.x

Bach, Kent 1999. “The Myth of Conventional Implicature.” Linguistics and Philosophy 22, 327-366. DOI: $10.1023 / \mathrm{a}: 1005466020243$

Bach, Kent 2006. "Pragmatics and the Philosophy of Language." In The Handbook of Pragmatics, edited by Laurence Horn \& Gregory Ward, Malden, MA: Blackwell, 463-487.

Blakemore, Diane 2002. Relevance and Linguistic Meaning: The semantics and pragmatics of discourse markers. Cambridge: Cambridge University Press.

Blakemore, Diane 2011. "On the Descriptive Ineffability of Expressive Meaning." Journal of Pragmatics 43, 3537-3550. DOI: 10.1016/j.pragma.2011.08.003

Boër, Steven E. \& Lycan, William G. 1976. "The Myth of Semantic Presupposition." Working Papers in Linguistics 21, 1-90. URL = $<$ https://kb.osu.edu/handle/1811/81405>

Borg, Emma 2004. Minimal Semantics. Oxford: Oxford University Press.

Cappelen, Herman 2018. Fixing Language: An Essay on Conceptual Engineering. Oxford: Oxford University Press.

Cappelen, Herman \& Lepore, Ernie 2005. Insensitive Semantics: A Defense of Semantic Minimalism and Speech Act Pluralism. Malden, MA: Blackwell. 
Chalmers, David 2011. "Verbal Disputes." Philosophical Review 120, 515-566. DOI: $10.1215 / 00318108-1334478$

Davis, Wayne 1998. Implicature: Intention, convention, and principle in the failure of Gricean theory. Cambridge: Cambridge University Press.

Dummett, Michael 1996. The Seas of Language. Oxford: Clarendon Press.

Ereshefsky, Marc 2008. "Systematics and Taxonomy." In: A Companion to the Philosophy of Biology, edited by Sahotra Sarkar \& Anya Plutynski, Malden, MA: Blackwell, 99118.

Frege, Gottlob 1892 “ Über Sinn und Bedeutung.” Zeitschrift für Philosophie und Philosophische Kritik 100, 25-50. (Translation in The Frege Reader, edited by Michael Beaney, Oxford: Blackwell 1997, 151-171.) (=SB)

Frege, Gottlob 1897. "Logik." In his: Nachgelassene Schriften, edited by Hans Hermes et al., Hamburg: Meiner 1983, 137-163. (Partial translation in The Frege Reader, edited by Michael Beaney, Oxford: Blackwell 1997, 227-250.) (=Logik)

Frege, Gottlob 1918/9. "Der Gedanke." Beiträge zur Philosophie des deutschen Idealismus 1, 58-77. (Translation in The Frege Reader, edited by Michael Beaney, Oxford: Blackwell 1997, 325-345.) (=Ged)

Frege, Gottlob 1923/6. “ Gedankengefüge.” Beiträge zur Philosophie des deutschen Idealismus 3: 36-51. (=Ggf)

Grice, H.P. 1961. "The Causal Theory of Perception.” Aristotelean Society Supplementary Volume 35, 121-153.

Grice, H.P. 1989. Studies in the Ways of Words. Cambridge, MA: Harvard University Press. Gutzmann, Daniel 2015. Use-Conditional Meaning. Oxford: Oxford University Press. Gutzmann, Daniel \& Turgay, Katharina 2019. "Secondary Content: An Introduction.” In: Secondary Content: The Semantics and Pragmatics of Side Issues, edited by Daniel Gutzmann \& Katharina Turgay, Leiden: Brill, 1-25.

Horn, Laurence 2002. "Assertoric Inertia and NPI Licensing." Proceedings of the Annual Meeting of the Chicago Linguistic Society 38/2, 55-82.

Horn, Laurence 2007. "Toward a Fregean Pragmatics: Voraussetzung, Nebengedanke, Andeutung." In: Explorations in Pragmatics, edited by Istvan Kecskes \& Laurence Horn, Berlin: de Gruyter, 39-69.

Horn, Laurence 2013. "I Love Me Some Datives: Expressive Meaning, Free Datives, and FImplicature." In: Beyond Expressives: Explorations in Use-Conditional Meaning, edited by Daniel Gutzmann \& Hans-Martin Gärtner, Leiden: Brill, 151-199.

Huntley, Martin 1975. "Presupposition and Implicature." Semantikos 1, 67-88.

Kaplan, David ms. "What is Meaning? Explorations in the theory of Meaning as Use."

Karttunen, Lauri 1973. "Presuppositions of Compound Sentences." Linguistic Inquiry 4(2), 169-193.

Keynes, John Neville 1894. Studies and Exercises in Formal Logic. 3rd ed. London: Macmillan.

Koev, Todor 2018. "Notions of at-issueness.” Language and Linguistics Compass 12, 1-16. DOI: $10.1111 / \operatorname{lnc} 3.12306$

Kripke, Saul 2009. "Presupposition and Anaphora: Remarks on the Formulation of the Projection Problem.” Linguistic Inquiry 40: 367-386. 
Lepore, Ernie \& Stone, Matthew 2015. Imagination and Convention: Distinguishing Grammar and Inference in Language. Oxford: Oxford University Press.

Lepore, Ernie \& Stone, Matthew 2018. "Slurs and Tone." In: Eva Picardi on Language, Analysis and History, edited by Annalisa Coliva, Paolo Leonardi \& Sebastiano Moruzzi, Cham: Palgrave Macmillan, 205-217.

Levinson, Stephen 1983. Pragmatics. Cambridge: Cambridge University Press.

Lewis, David 1979. “Scorekeeping in a Language Game.” Journal of Philosophical Logic 8, 339-359.

Ludlow, Peter 2014. Living Words: Meaning Underdetermination and the Dynamic Lexicon. Oxford: Oxford University Press.

McCready, Elin 2014. "Expressives and Expressivity." Open Linguistics 1, 53-70. DOI: 10.2478/opli-2014-0004

McCready, Elin 2019. The Semantics and Pragmatics of Honorification: Register and Social Meaning. Oxford: Oxford University Press.

Potts, Christopher 2005. The Logic of Conventional Implicature. Oxford: Oxford University Press.

Potts, Christopher 2015. "Presupposition and Implicature." In: The Handbook of Contemporary Semantic Theory, edited by Shalom Lappin \& Chris Fox, Malden, MA: Wiley Blackwell, 168-202.

Predelli, Stephano 2013. Meaning without Truth, Oxford: Oxford University Press.

Recanati, François 2006. "Crazy Minimalism.” Mind \& Language 21, 21-30. DOI: 10.1111/j.1468-0017.2006.00303.x

Rett, Jessica 2021. "The Semantics of Emotive Markers and Other Illocutionary Content." Journal of Semantics 38, 305-340. DOI: 10.1093/jos/ffab005

Rett, Jessica forthcoming. "A Comparison of Expressives and Miratives." URL = $<$ https://linguistics.ucla.edu/people/Rett/Rett 2020 expressives.pdf $>$

Sander, Thorsten 2019. "Two Misconstruals of Frege's Theory of Colouring." The Philosophical Quarterly 69, 374-392. DOI: 10.1093/pq/pqy054

Sander, Thorsten 2021. "Fregean Side-Thoughts.” Australasian Journal of Philosophy 99:3, 455-471. DOI: 10.1080/00048402.2020.1795216

Sander, Thorsten 2021a. "Understanding Frege's notion of presupposition." Synthese, online first. DOI: $10.1007 / \mathrm{s} 11229-021-03346-7$

Saul, Jennifer 2012. Lying, Misleading, and What Is Said: An Exploration in Philosophy of Language and in Ethics. Oxford: Oxford University Press.

Schlenker, Philippe 2007. "Expressive Presuppositions." Theoretical Linguistics 33-2, 237245. DOI: $10.1515 /$ TL.2007.017

Simons, Mandy \& Tonhauser, Judith \& Beaver, David \& Roberts, Craige 2010. "What projects and why." Proceedings of SALT 20, 309-327.

Soames, Scott 1989. "Presupposition." In: Handbook of Philosophical Logic IV: Topics in the Philosophy of Language, edited by D. Gabbay \& F. Guenther, Dordrecht: Reidel, 553616.

Sorensen, Roy 2017. "Lucifer's Logic Lessons: How to Lie with Arguments." Aristotelean Society Supplementary Volume 91, 105-126. DOI: 10.1093/arisup/akw016

Stalnaker, Robert 1999. Context and Content: Essays on Intentionality in Speech and 
Thought. Oxford: Oxford University Press.

Stalnaker, Robert 2002. "Common Ground." Linguistics and Philosophy 25, 701-721. DOI: 10.1023/A:1020867916902

Stokke, Andreas 2017. "Conventional Implicature, Presupposition, and Lying." Aristotelean Society Supplementary Volume 91, 127-147. DOI: 10.1093/arisup/akx004

Tonhauser, Judith 2015. “Are 'informative presuppositions' presuppositions?” Language and Linguistics Compass 9/2, 77-101. DOI: 10.1111/lnc3.12119

Tonhauser, Judith \& Beaver, David \& Roberts, Craige \& Simons, Mandy 2013. "Toward a Taxonomy of Projective Content." Language 89, 66-109. DOI:

10.1353/lan.2013.0001

Väyrynen, Pekka 2013. The Lewd, the Rude and the Nasty: A Study of Thick Concepts in Ethics. Oxford: Oxford University Press.

Viebahn, Emanuel 2020. “Lying with Presuppositions.” Nôus 54, 731-751. DOI:

10.1111 /nous. 12282

Wilson, Deirdre 2016. "Reassessing the conceptual-procedural distinction." Lingua 175-176, 5-19. DOI: 10.1016/j.lingua.2015.12.005

Wilson, Deirdre \& Sperber, Dan 1993. "Linguistic form and relevance." Lingua 90, 1-25. DOI: 10.1016/0024-3841(93)90058-5 